\title{
Health Insurance Regime as Differentiation and Discipline: The Chinese Health Insurance Reforms
}

\author{
Jiong $\mathrm{Tu}$
}

\section{Introduction}

Health care in the Chinese official discourses is expressed as a right. At the First National Health Work Conference in 1950, soon after the founding of the People's Republic of China (in 1949), health care was declared as a right. It laid down healthcare guidelines oriented towards 'workers, peasants and soldiers'. ${ }^{1}$ The constitution, ${ }^{2}$ first promulgated in 1954 and later revised many times, denoted that the state should develop various medical and health care facilities to protect people's health (Article 21), that Chinese citizens should have the right to get material help from the state and society when they are old, sick, or lose their working ability, and that the state will develop social insurance, social aid, and medical and health care work to meet these rights of citizens (Article 45). In the collective era (from 1950s to 1970s), China had provided basic health care to most of its population. Health care then was consisted of health care for workers under the Labour Insurance Scheme (LIS, laobao yiliao), mainly funded by the welfare funds of enterprises, providing employees and their immediate family members with full or partial medical care coverage; public health care for government employees through the Government Insurance Scheme (GIS, gongfei yiliao), financed directly by governments at various levels, provided to people working in government and public institutions, including the staff of cultural, educational, health, and research institutes, and students at colleges and universities; and the rural Cooperative Medical Scheme (CMS, hezuo yiliao) for peasants, funded by contributions from participants and heavily subsidised by the rural collective welfare funds and government.

1 Shaoguang Wang, "China's Double Movement in Health Care," Socialist Register, 46 (2010), 240-61.

2 Central People's Government, PRC. The Constitution of the People's Republic of China (Zhonghua renmin gongheguo xianfa), Retrieved 2 June, 2013 (http://www.gov.cn/gongbao/content/2004/content 62714.htm). 
However, things began to change with the advent of market reforms in the 1980s. The healthcare system underwent a transition, from fully state-run, financed care to more privately financed and delivered health care. The collective production system that supported rural health care was replaced by the household production system in the 1980s. The rural CMS and collective medical facilities could not be sustained anymore. ${ }^{3}$ Besides, the role of "work units" in providing health insurance to urban employees has been greatly weakened as they were required to become more efficient in the market. Many public employees "dove into the business sea" (xiahai) or were laid off by their work units, ${ }^{4}$ becoming responsible for their own health care. Together with the collapse of rural cooperative medical insurance scheme, health insurance coverage in China has decreased to the minimum, leading to a rapid increase in direct out-of-pocket payment. ${ }^{5}$ The former universally available (basic) health services were no longer available to all. Many patients were left to shoulder their own health care expenses. Some even fell into poverty due to illness. In 2000, China was ranked close to the bottom (188th out of 191 member countries) in terms of the fairness of health care financing and ranked 141st in terms of the health system's overall performance by the World Health Organisation. ${ }^{6}$

Only after the outbreak of SARS in 2003, China started to implement a new round of healthcare reform that is attempting to reverse the market character of earlier trajectories. The new healthcare reform reemphasises citizens' entitlement to health care as a basic right. It denotes that the government should do its utmost to fulfil its duty in building the health system, in providing public health care, and in protecting

3 Since the early 1980s, the rural cooperative medical insurance system has collapsed, only $5.4 \%$ of China's 940,000 villages had cooperative medical care in 1985 and 15\% in 1994, though this figure was approximately $90 \%$ in the late 1970s. From Wu, Yanrui, "China's Health Care Sector in Transition: Resources, Demand and Reforms,” Health Policy, 39: 2 (1997), 148.

4 From 1995 to 2002 alone, about 60 million employees were cut from state or collective enterprises. From Xing Ying, "Barefoot Lawyers and Rural Conflicts," in Y. T. Hsing and C. K. Lee, eds., Reclaiming Chinese Society: The New Social Activism, (New York, 2010), p. 3.

5 In the mid-1990s, approximately 95 percent of rural residents were paying for their own care. Even with the government's efforts to change the situation since the late 1990s, the Third National Health Service Research in 2003 still showed that about 65 percent of the population (45 percent of urban population, and 70 percent of rural population) did not have any insurance. From Colleen M Grogan, "Urban Economic Reform and Access to Health Care Coverage in the People's Republic of China," Social Science \& Medicine, 41: 8 (1995), 1073-1084, and Xin Gu, Towards Universal Coverage of Healthcare Insurance: The Strategic Choices and Institutional Frameworks of China's New Healthcare Reform. (Beijing, 2008), p. 60.

6 World Health Report 2000. Retrieved 20 December, 2010 (http://www.who.int/whr/2000/en/). 
people's health rights. ${ }^{7}$ The official healthcare reform agenda was released in $2009,{ }^{8}$ which aims to establish a state-sponsored health system that provides universal (basic) health care coverage. One of the main reform agendas is to set up a basic health insurance system that provides insurance for all. It includes health insurance for urban employees (introduced in 1998), jointly paid for by governments, employers and employees; health insurance for unemployed urban residents (since 2007), mainly paid for by residents and subsidised by governments; and a new cooperative medical insurance scheme for rural residents (since 2003), co-paid by governments and individuals. The government provides subsidies for the poor to take out medical insurance. There is also a medical aid system for patients with "major illness" or those facing financial difficulty. Commercial insurances are also encouraged to complement the state health insurances. Recent research shows that 95 percent of the Chinese population had some form of health insurance by the end of 2011, up from less than one-third in 2003.'

Situate in this grand transformation, this article analyses the function of China's new health insurance schemes. The article is based on the ethnographic research in Riverside County (pseudonym) of Sichuan Province from 2011 to 2012, involving semi-structured interviews and conversations with patients, health professionals, health administrators and officials, participant observation in medical institutions, and document research. In Riverside County, many patients have benefited from recent new insurance programmes. Health insurance programmes have also been proclaimed by local health professionals as the most, or even the only, successful part of the new healthcare reform. Nevertheless, this article holds a more critical view to analyse the function of health insurance as a mechanism of governance and differentiation.

From the perspective of governmentality, insurance can be considered as a "technology of risk"10 that organises people to share the burden of risks involved in life. Francois Ewald notes that insurance as "a distributive sharing of a collective burden" contains a social rule of justice and a principle of social solidarity, which is

7 See Talk by Gao Qiang (the Minister of the Ministry of Health) in 2005, "Developing Medical and Health Work, Making Contribution to Build a Socialist Harmonious Society" (Fazhan yiliao weisheng shiye, wei goujian shehuizhuyi hexieshehui zuo gongxian), People's Net. Retrieved 13 April, 2011 (http://politics.people.com.cn/GB/1027/3590082.html).

8 See the "Opinions of the CPC Central Committee and the State Council on Deepening the Health Care System Reform" (Zhonggong zhongyang guowuyuan guanyu shenhua yiyao weisheng tizhi gaige de yijian), 2009. Retrieved 27 January, 2011 (http://www.gov.cn/jrzg/200904/06/content 1278721.html).

9 Chen Gao, Fei Xu, and Gordon G. Liu, "Payment Reform and Changes in Health Care in China," Social Science \& Medicine, 111 (2014), 10-16.

10 Francois Ewald, "Insurance and Risk," in G. Burchell, C. Gordon and P. Miller, eds., The Foucault Effect: Studies in Governmentality with Two Lectures by and an Interview with Michel Foucault (Chicago, 1991), p. 197. 
different from the judicial idea of deciding accident compensation following an investigation of the cause of injury. ${ }^{11}$ However, the new health insurance schemes in China contain contradictory and competing ideas. Health insurance is organised with the hope of improving social justice through the distribution of health care burden collectively. Yet the implementation of insurance schemes follows the judicial model. Insurance reimbursement is linked with the investigation of the cause of injury - the evaluation of whether the illness or injury was due to natural causes (in that case the insurance will cover the medical bill) or due to the behaviour of individuals (in that case the individual should bear the medical costs). The definition of "qualified" patients in the health insurance regime serves as the gatekeeper to safeguarding the insurance funds targeting the needy people, but it also produces new differentiation, discrimination, and inequality among patients. Health insurance policies combined with other state policies (for instance household registration, population control, and employment status) produce categories and qualifications that subject patients to a structure of selection and means-testing. It also provides the authority with new mechanisms of surveillance and control, and enables more efficient governance. Health insurance regimes form the basis of biopower and constitute the power/knowledge ${ }^{12}$ in Foucauldian sense to monitor, shape and control the behaviour of individuals as well as the conduct of the population. This article explores how health insurance regimes constitute regulatory devices, enable the evaluation of the qualification and worthiness of patients, and correspondingly serve to extend the state control and surveillance of individuals and the population. In the process, it also produces new discriminations and inequalities among Chinese patients.

\section{Health Insurance as Segregation: the Exclusion of Migrants}

Rural-to-urban migrant workers have been widely researched in China. Migrant workers take the dangerous, difficult and dirty jobs that the urban residents are not willing to do. They have low social status and unequal access to public services in the city, and are referred to by scholars as the "second-class citizen" ${ }^{13}$. When migrants work in the city, only some well-functioned companies provide health insurance, which is co-contributed by workers and employers. Many migrants cannot get health

11 Francois Ewald, "Insurance and Risk," in G. Burchell, C. Gordon and P. Miller, eds., The Foucault Effect: Studies in Governmentality with Two Lectures by and an Interview with Michel Foucault (Chicago, 1991), p. 206.

12Michel Foucault, Power/knowledge: Selected interviews and other writings, 1972-1977 (New York, 1980).

13 Dorothy Solinger, Contesting Citizenship in Urban China: Peasant Migrants, the State, and the Logic of the Market (Berkeley, 1999). M. King Whyte, One Country, Two Societies: Rural-urban Inequality in Contemporary China (Cambridge, 2010). 
insurance in their working place and, as a result, confront serious health care exclusion. A 40-city survey conducted by State Council in 2004 shows that only 15 percent of migrant workers participate in social security schemes and only 10 percent have medical insurance. ${ }^{14}$ In the new healthcare reform, the state has developed health insurance for urban employees, insurance for unemployed urban residents, and cooperative medical scheme for rural residents, but no suitable insurance programme is available to migrant workers, many of who are peasants but work and live in the city. The health insurance system is coordinated within the jurisdiction territories of each municipality and is linked to people's household registration (bukou). The use of health insurance is restricted to assigned hospitals and pharmacies in places where people's hukou is located. If patients seek health care in other places, they either pay out-of-pocket or go to the assigned hospitals outside their municipality with a low reimbursement rate. The segregated and fragmented health insurance system cannot meet the demands of the increasingly mobile Chinese population. In 2012, the number of migrants in China was 236 million. ${ }^{15}$ In Riverside County, about one fourth of the population, over 250,000 people, annually migrate to seek job. The market economy creates these free floating workers, but the existing system does not provide a portable or national level medical scheme to protect them. By examining this marginal group in the current health system, this section tries to understand how the health insurance scheme shapes and facilitates a process of exclusion in health care governance.

\section{The Migrant Worker Who Got a Brain Tumour}

In September 2012, during my week-long observation in the rehabilitation department of a local public hospital, I met a brain tumour patient, a young migrant worker in his early 30s, who was being treated in the department. I talked with him over the week and got to know his story. In April 2012, the migrant worker had fainted at the construction site he worked at, in Henan province. His colleagues called the ambulance. In the hospital, the MRI scan showed a tumour in his brain. He got emergency treatment in Henan province, which cost him over 10,000 Yuan, several months of his salary. Soon after the emergency treatment, he migrated back to his home province Sichuan. He registered in Huaxi Hospital, the best hospital in the provincial capital. The main site of the hospital was full and could not accommodate any more patients, so he was accommodated in the hospital's newly-

14 Ching Kwan Lee and Yuan Shen, "The Paradox and Possibility for a Public Sociology of Labor in China," Work and Occupations, 36: 2 (2009), 110-125.

15 National Health and Family Planning Commission, PRC. "Summary of the 2013 Reports on the Development of China's Migrant Population" (<Zhongguo liudong renkou fazhan baogao 2013> neirong gaiyao), 2013. Retrieved 10 October, 2013 (http://www.nhfpc.gov.cn/ldrks/s7847/201309/12e8cf0459de42c981c59e827b87a27c.shtml). 
built sub branch situated in the suburb. Doctors from the main hospital came to operate on him several days later. After the operation, he stayed in the hospital for about a month. Later on he was transferred to the Provincial Tumour Hospital, another top level hospital in the provincial capital, where he got regular medical checks and radiotherapy for two months. The tumour hospital was also full. The department he visited only had 50 beds, but there were more than 80 inpatients. "How expensive health care is in those big hospitals!" he exclaimed. The operation in Huaxi Hospital cost him more than 36,000 Yuan. Each time he visited the Tumour Hospital, the MRI scan would cost more than 2,000 Yuan and radiotherapy cost more than 4,000 Yuan, not to mention other expenses. The overall medical expenditure since his first hospitalisation had already surpassed 100,000 Yuan, a huge amount for most Chinese families, let alone for a peasant like himself. He had bought rural health insurance annually, but he predicted that he might only claim back about 20 to 30 percent of his expenditure. Most of his treatments were in places outside Riverside County (the Henan province where his tumour was diagnosed and the provincial capital where he got operation and radiotherapy). The insurance scheme encourages patients to seek health care in low level medical institutions before going to higher level hospitals by giving higher reimbursement rates for hospital care at the bottom level. In 2012, the reimbursement rate of rural CMS in Riverside County was 90 percent for medical expenditure beyond 100 Yuan in township level hospitals; 80 percent for costs that exceeded 200 Yuan in county level hospitals; 60 percent for expenditure beyond 600 Yuan in municipal level hospitals; 55 percent for costs beyond 700 Yuan in provincial level hospitals and appointed hospitals outside the province; and for treatment in other hospitals, the reimbursement rate was 45 percent for costs beyond 800 Yuan (see Table 1). The tumour patient would be reimbursed at the lowest rate for his treatment in Henan province and the provincial hospitals, because he did not know that he should have obtained a hospital transfer reference from his local county hospital first. Doctor Chen in the rehabilitation department commented that many patients in serious and emergency situations, like this tumour patient, would go directly to high level hospitals or hospitals near their work places, and therefore would not be able to obtain the transfer reference from their hometown hospital in the first place. Besides, the health insurance only covers the items on the name lists of drugs, treatments, and medical facilities. In the tumour patient's case, many expensive drugs and tests were not covered by his insurance. The tumour patient's prediction of 20 to 30 percent reimbursement is consistent with other patients' experiences. In the field, I collected dozens of lists (displayed in local hospitals I visited) of patients who had received reimbursements between 2010 and 2012. Rural CMS patients on these lists, who had sought health care outside the local municipality, were generally reimbursed around, or less than, 30 percent of their overall medical expenditure. 
Table 1. CMS Reimbursement at Different Levels of Hospitals in 2012

\begin{tabular}{lccc}
\hline Hospital Level & $\begin{array}{c}\text { Reimbursement } \\
\text { for costs } \\
\text { exceeded }\end{array}$ & $\begin{array}{c}\text { Reimbursement } \\
\text { rates }\end{array}$ & $\begin{array}{c}\text { Reimbursement } \\
\text { ceilings }\end{array}$ \\
\hline $\begin{array}{l}\text { Township hospitals } \\
\text { County hospitals }\end{array}$ & $\begin{array}{l}\text { 200 Yuan } \\
\text { Appointed municipal }\end{array}$ & $90 \%$ & 120,000 Yuan \\
$\begin{array}{l}\text { hosp Yuan } \\
\text { hospitals }\end{array}$ & $60 \%$ & 120,000 Yuan \\
$\begin{array}{l}\text { Appointed provincial } \\
\text { hospitals and appointed } \\
\text { hospitals outside the } \\
\text { province }\end{array}$ & 700 Yuan & $55 \%$ & 120,000 Yuan \\
$\begin{array}{l}\text { Other (non-appointed) } \\
\text { hospitals outside the } \\
\text { municipality }\end{array}$ & 800 Yuan & $45 \%$ & 120,000 Yuan \\
\hline
\end{tabular}

Source: Collected by the author in Riverside County.

After treatment in the provincial capital, the migrant worker came back to Riverside County. He came to the local hospital daily for acupuncture and rehabilitation. During the week I observed at the hospital, the tumour patient constantly asked the doctors about his medical expenditure. In the long acupuncture process, he frequently lamented that only his elder brother was earning money to support the family since he got sick. His previous treatments had already cost more than 100,000 Yuan and he needed more money for the ongoing rehabilitation and further radiotherapy. Other patients in the same ward often gave him suggestions on what social assistance was available and how to apply from the government. I suggested that he should apply for the medical aid for major illnesses. He told me that he needed to wait until the Health Insurance Bureau approved his reimbursement, only then could he take the insurance reimbursement documents to apply for further medical aid from the Bureau of Civil Affairs. "I might get 2,000 to 4,000 [Yuan medical aid]," he predicted. The medical aid aims at helping poor families to counter major illnesses. Being mainly funded by the local level governments and supplemented with subsidies from the central government and social donations, the capacity of medical aid is limited. A report from the Riverside County Bureau of Civil Affairs showed that in 2010 it had given medical aid to 16,484 people in the urban area, which amounted to 3,466,800 Yuan. However, when this was distributed to individual patients, each patient received on average about 210 Yuan in aid. Since the setting up of rural CMS in Riverside (in 2005), the Bureau of Civil Affair initiated a "second medical aid" for poor rural families to get up to 20,000 Yuan aid in cases of serious illnesses. The official data though, show that the total amount used in second aid was 138,000 Yuan in 2005, 600,000 Yuan in 2006, 1 million in 2007, and $1,137,015$ Yuan in 2009. In 2006, the 600,000 Yuan aided only 136 patients, giving 
less than 5,000 Yuan on average per patient. In 2009, the 1,137,015 Yuan aided 415 serious patients (whose medical fee surpassed 30,000 Yuan), but each patient on average only got about 2,700 Yuan in aid. A list of about 70 patients in a local town who got the "second medical aid" in 2008 showed that most of them only received 1,500 Yuan in aid, although all of these patients' medical expenditure surpassed 20,000 Yuan. Without any special connection, the tumour patient had good reason to predict that he might only get a few thousands Yuan in aid, merely a drop in the bucket of the total expenses.

\section{Bureaucratic Regulations, Social Separation and Exclusion}

The tumour patient's case reveals the many obstacles migrant workers face in general in order to get health care. These include a fragmented health insurance system, the bukou system that ties health care and other social services with people's place of origin, overcrowded hospitals, exorbitant medical charges, low insurance reimbursement, complex and unclear policies, and so forth. The different insurance schemes that organise people together in the sharing of risks also produce separation among patients who are divided into different patient statuses. While people now have more access to social assistance, the rural population are still extremely vulnerable when facing major illnesses. Even for those who receive insurance reimbursement, the funding is frequently inadequate. Moreover, various rules and policies constitute a corpus of insurance knowledge, which people are not familiar with. The information billboards displayed around hospitals and insurance bureaus only provide a general introduction about health insurance policies. There is no detailed insurance regulation (such as insurance coverage item list, reimbursement procedures) available on-line or given to the public, and reimbursement policies change from year to year. The locals have to go to the insurance office to enquire in person. The migrant's case also points towards the overly bureaucratic approach of insurance administration. Health insurance schemes are administered by several departments separately. Health insurance for urban employees and urban residents are administered by the Social Insurance Department at different levels of government under the Ministry of Human Resources and Social Security. The rural CMS is administered by the Rural Health Insurance Bureau under the Ministry of Health. Medical aid is under the administration of yet another department - the Ministry of Civil Affairs. The overly bureaucratic arrangement makes reimbursement procedures lengthy and complex. Patients have to pay medical fees out of pocket first, and get reimbursed after their treatment. The reimbursement process involves many procedures and a mass of paper work. After several months from his first hospitalisation, the migrant worker had not received any benefit. The over- 
bureaucratic arrangements sometimes deter people from seeking proper health care and insurance benefits.

In China, the urban areas for a long time have been the privileged sites of medical services and facilities, which, however, are not available for migrant workers. Many literatures have recorded the poor access to proper health care for migrants in the urban areas, and the health risks of migrants, including psychological distress and mental health problems, infectious diseases, maternal health, occupational disease and injuries, and poor long-term health. ${ }^{16}$ The combination of health insurance schemes and the hukou system produces exclusions for migrant workers, disabling them from receiving affordable health care in the city. The return of migrants to their hometown to seek health care may overwhelm the newly-built rural insurance system. ${ }^{17}$ The movement of goods and labours in the market economy is not matched with the flexibility of social services. Public services continue the rigid separation between localities, between rural and urban areas, that has been in place since the collective era. These fragmentation and segregation impair labour mobility (which is fundamental to China's economic development) and social solidarity.

In early 2012, the central government released a series of new health reform targets for the following years, including giving migrant workers more equal access to medical services. ${ }^{18}$ Some local governments have experimented in supplying social security programmes for migrant workers but, without proposed funding mechanism, most local governments are not willing to provide migrants with appropriate public services that need to be supported by the local finance. Feng $\mathrm{Xu}$ argues that the governmental attitude towards migrant workers was not to "let" them "die", but it was more about letting them "move" rather than making them "live".19 My research on health care access suggests that migrant workers are either "let" to die

16 Juan Chen, "Internal Migration and Health: Re-examining the Healthy Migrant Phenomenon in China," Social Science \& Medicine 72: 8 (2011), 1294-1301. Therese Hesketh, Xuejun Ye, Lu Li and Hongmei Wang, "Health Status and Access to Health Care of Migrant Workers in China," Public Health Reports 123: 2 (2008), 189-197. Xiaojiang Hu, Sarah Cook and Miguel A. Salazar, "Internal Migration and Health in China," The Lancet, 372: 9651 (2008), 17171719. Yingchun Peng, Wenhu Chang, Haiqing Zhou, Hongpu Hu, and Wannian Liang, "Factors Associated with Health-seeking Behavior among Migrant Workers in Beijing, China," BMC Health Services Research, 10:69 (2010).

17 Xiaojiang Hu, Sarah Cook and Miguel A. Salazar, "Internal Migration and Health in China," The Lancet, 372: 9651 (2008), 1717-1719.

18 Central People's Government, PRC. "Guidance on Setting up Emergency Medical Aid System from General Office of the State Council of the People's Republic of China” (Guowuyuan bangongting guanyu jianli jibing yingji jiuzhu zhidu de zhidao yijian), 2013. Retrieved 2 March, 2013 (http://www.gov.cn/zwgk/2013-03/01/content 2342656.htm).

19 Feng Xu, "Governing China's Peasant Migrants: Building Xiaokang Socialism and Harmonious Society," in E. Jeffreys, eds., China's Governmentalities: Governing Change, Changing Government (London, 2009), p. 40. 
in the city ${ }^{20}$ or expected to "move" back to their hometown to "live" (such as the tumour patient above). The labour of these young, healthy migrant workforces contribute to the improvement of living conditions in the urban areas and to the economic prosperity in China. The city also provides millions of migrant workers with a chance to earn more, and thus improves the lives of migrants and their families, but only when they are healthy. When illness comes, the city fails to provide them with protection. Referring to Foucault, Gay Becker writes that marginality reflects "the biopolitical division between those whose lives are managed with the goal of enhancement and those whose lives are judged as less worthy and who are allowed to die." ${ }^{21}$ Lacking education and "quality" in the neoliberal market, migrant workers rely mainly, even solely, on their "healthy" bodies to support their lives in the city. When they become sick and (temporarily or permanently) lose their "productivity," they become "valueless," experience indifference, and are driven away from the city back to their hometowns in order to survive.

\section{Health Insurance as Regulatory Technology}

Health insurance schemes have specific regulations for the categorisation and qualification of patients. These regulatory rules vary from place to place, but generally there are several shared categories of illnesses or treatments that are not covered by the three main insurance schemes: injuries caused in traffic accident, medical accident, or other accident due to negligence $;^{22}$ injuries caused by one's drug-taking, fighting, or other illegal behaviour; treatment due to individual self-harm, suicide, alcoholism, etc.; medical treatment sought by oneself (a patient does not go to the

20 There are many media reports of "letting patients die" cases in China. A well-known incident occurred in 2012 when a migrant worker was left to die under a bridge, a spot where many migrant workers camped at night in Henan Province. The migrant worker had been ill for more than 20 days. A few days before his death, people called an ambulance. The emergency doctor came and examined him, found that his symptoms were normal, but asked him to go to the hospital for further checks. The patient refused. The ambulance then left, leaving the patient untreated. The worker died a few days later. See "Ambulance Failed to Save Dying Migrant, Zhengzhou Government Responded: Patient Refused to Go to Hospital" (Zhengzhou huiying mingong jietou binsi 120 jianerweijiu: huanzhe jujue jiuyi), 2012. Retrieved 19 February, 2013 (http://www.chinanews.com/sh/2012/12-02/4374931.shtml).

21 Gay Becker, "The Uninsured and the Politics of Containment in U.S. Health Care," Medical Anthropology, 26: 4 (2007), 300.

22 This regulation is especially unfavourable for migrant workers. The rural CMS, the insurance most rural-to-urban migrant workers have, does not cover industry injuries - injuries caused during work, because it presumes that the industry injuries will be covered by the labour insurance. However, it ignores the large numbers of migrant workers, who take dangerous work in the city and have high possibility of getting injured during work, but frequently do not have labour insurance. 
appointed hospital or does not get a transfer reference before going to a high level hospital); drugs or treatments outside insurance coverage; medical treatment for cases that are not in accordance with birth planning policies. ${ }^{23}$ These regulations construct a "grid of abstract categories" that works as normative rules and judgements. They encourage people to be responsible subjects, not hurt themselves intentionally, and take responsibility themselves or seek compensation from the person who caused their injuries rather than rely on the public insurance. They also produce the "civic worthiness" of health care according to individual's conduct. Injuries caused by irresponsible or "immoral" acts, such as fights, alcoholism, and criminalities, are "unworthy" of state covered health care. The individual is "objectively" evaluated by these criteria which constitute a punitive gaze, surveying individual behaviour, but frequently failing to acknowledge individual's entitlement.

\section{The "Unqualified" Patient under Population Control}

In Riverside, I recorded many cases of insured people who were only partiallyqualified or unqualified for health insurance coverage. The pre-marriage birth is one of the unqualified categories. One such case involved a 19-year-old who gave birth to a baby by caesarean in the county hospital in 2012. After the birth, the preterm baby was sent to the municipal hospital for intensive care. The overall medical costs of the mother and baby were over 10,000 Yuan, but neither of them could get any reimbursement, although the mother had joined the CMS. The CMS proclaims that it covers all the fees of a natural delivery and part of the costs of a caesarean. However, in order to get the benefit, the birth must take place in the appointed medical institution with a birth permit (zhun shengzheng). The birth permit is a certificate obtained by married couples to legitimate a birth, a policy related with the population control currently carried out in China. Only those who abide by state birth policies (married couples, one child in most cases) can obtain medical insurance reimbursement. The young mother, unmarried, could not get the birth permit. Her pregnancy thus became "undesired" and the baby was a result of an "unwanted birth" according to the state policy. The young mother was not entitled to insurance coverage for the birth. The baby, born out of marriage, would encounter more difficulties to obtain a hukou, without which he would not be able to get the newborn baby medical insurance. Thus, the baby had no coverage for his earlier treatment. Besides, the ethical environment in the local community has not changed as quickly as the economic development and sexual behaviour of young people. Premarital pregnancy is still highly stigmatised and frequently becomes the target of

23 The lists are based on the local health insurance reimbursement regulations and the internet search results about health care that is not covered by various insurance schemes. 
gossip within a community. ${ }^{24}$ The family, embarrassed by the "dishonoured" birth, could hardly speak out in the community, let alone fight for their insurance entitlement.

Population governance in China has relied on both the cruder disciplinary practices (sometimes coercive abortion) and more subtle controls such as the link of birth with health insurance and other welfare benefits. Birth control in China has been relaxed recently. The coercive elements in population control, although still occasionally exposed by the media, have been used much less frequently over the years. ${ }^{25}$ The disciplinary techniques have become more subtle forms, which work to shape and guide individual conduct. ${ }^{26}$ The state-initiated propaganda and policies that stigmatise and discriminate unmarried birth also serve the birth control. State policies, together with social norms, construct the standards of appropriate behaviour and a moral form of self-governance where an unmarried young woman is expected to control her own reproductive activities. The link of social welfare to birth behaviour materialises this control. ${ }^{27}$ When an "illegal" birth occurs, the health insurance exposes the patient to new punitive regulatory techniques, adding embarrassment to the already embarrassed family. Health care thus facilitates the surveillance and control of the population.

Greenhalgh ${ }^{28}$ suggests that China's population-planning creates legal "nonpersons" out of those born "out-of-quota." The unplanned births give rise to "unplanned persons" who have no access to schools, village land, etc., and thus in essence creates "stratified citizenship." In health care, these "unplanned babies" and women with "unplanned pregnancy/birth" are excluded from health care entitlement. Children and women, who come from more economically vulnerable families and need insurance reimbursement more than others, tend to be more

24 I first heard about this case through the gossip by a group of elderly women in a local community. Later I got more information about this case through interviews with several community members. But when discussing this case, all of them immediately lowered their voices.

25 Therese Hesketh, 'China's One-child Policy is Slowly Being Eased'. The Guardian. 2010. Retrieved 5 May, 2014 (http://www.theguardian.com/commentisfree/2010/oct/24/china-onechild-policy-eased).

26 Greenhalgh and Winckler (2005) find, in China's population control, the neoliberal biopolitics emerge in the people's effort to produce the 'quality child'. They notes that the reproductive self-discipline is a kind of regulated freedom, guided by powerful logics of science and technology, the market, and the transnational consumer culture; it is produced by forces seeking to shape individual desires and behaviour to their own ends. Greenhalgh (2009) further notes that bio-governance in China aimed at the management of the vital characteristics of human populations, and exercised in the name of optimising individual and collective life, health, and welfare.

27 The link of social services with social-control mechanism has long been used by the party-state since the Maoist period.

28 Susan Greenhalgh, "Planned Births, Unplanned Persons: 'Population' in the Making of Chinese Modernity," American Ethnologist, 30: 2 (2003), 196-215. 
affected by these policy "penalties," because they have less resources and connections to overcome policy obstacles. Health insurance produces a diffuse apparatus of power/knowledge with normative power that endorses certain values and behaviour while rejecting others that are not in accordance with the government's aims. The health care right - the right to get insurance benefits here - is a matter ratified by the state, rather than a right given at birth. The actual entitlement is based on neither need nor right, but on rule abidance. Through the deployment of insurance regulatory, the individual and social body become more pliable and amenable. Insurance enables the beneficiary's "voluntary" compliance. However, people also subtly negotiate their insurance entitlements.

\section{Becoming Qualified Patients: Negotiate Insurance Reimbursement}

Insurance qualifications form a controlled sphere of "normal" and "abnormal" illnesses. People respond by seeking to become the "qualified" or legitimate patients. Aunt Wen, a local resident in her 60s, broke her collarbone in May 2011, when she fell from her husband - Uncle Wen's motorbike. Uncle and Aunt Wen recounted to me in detail how Aunt Wen was hospitalised and reimbursed:

Uncle Wen: We were opportunistic this time. When she broke her bone, we hadn't bought health insurance yet. I went [to the community office] to ask whether health insurance was still for sale, he [the staff] told me it was. I asked that if I bought the insurance could I use it immediately, he said it could cover hospitalisation that happened from January this year. On the second day I bought insurance for both of us, and then we went to the hospital [laugh]...Later we got more than 60 percent reimbursement. Before reimbursement, they would come to investigate the case, inquiring how she got hurt. When we just went into hospital, I said she fell down from my motorbike, but falling down from motorbike wouldn't be reimbursed, thus I said she fell down from the stair when going downstairs to shopping.

JT: How did you know motorbike accidents wouldn't be covered?

Aunt Wen: They told us. When we just went into hospital, the other patients nearby [in the same ward] asked us how I broke my bone, we told them I fell off from motorbike, they told us we wouldn't be reimbursed if we wrote falling off from motorbike. My eldest daughter hearing this immediately threw the [insurance claim] form she had already filled, she did business and was very "cunning." Later she asked the doctor for another form. She said she forgot where the first one was. (Interview P11) 
Aunt Wen was an urban resident and could join the health insurance for urban residents by paying an annual fee, which would cover hospital care for a year period (not for accumulation). In 2011, it cost 170 Yuan to join the insurance scheme. The health insurance specifies that the coverage scope of injuries directly caused by individual actions of the patients or others would not be covered, such as transport accidents. Instead of getting this information from the hospital or health professionals, Aunt Wen learnt this from other patients in the same ward, who frequently shared information with each other. Her family then made another excuse for her injury. Later on, the insurance bureau came to investigate Aunt Wen's case. Aunt Wen made up a detailed story about how she fell down from the stair outside her home when going out for shopping. In Aunt Wen's treatment, an expensive steel plate was installed to fix her broken bone. The whole medical expenditure was about 10,500 Yuan. Aunt Wen claimed back 6,700 Yuan from insurance, and thus paid only about 3,800 Yuan out of her own pocket. Aunt and Uncle Wen felt happy about this result and proclaimed that the insurance scheme was great. "You pay a little but get a lot," Uncle Wen commented. We all laughed when Uncle Wen said humorously that they were speculators who went to the hospital immediately after purchasing their health insurance. Patients like Uncle and Aunt Wen pragmatically took advantage of the state rules and adapted to the circumstance to gain benefits. The definition of "qualified" and "unqualified" patients is a subtle negotiation process that both the insurance bureau and the patient take part in, rather than simply a label allocated from above.

Nobody felt that it was "illegal" to "make the story up" and "take advantage of the policy," but rather, everyone felt happy for the result that Aunt Wen finally got reimbursed. Their "opportunistic" action was morally justified, considering that normal patients frequently suffered heavy burdens in the commercialised health care sector. As Ong and Zhang write, increasingly, in contemporary China, "individuals are obliged to exercise diligence, cunning, talents, and social skills to navigate evershifting networks of goods, relationships, knowledge, and institutions in the competition for wealth and personal advantage". ${ }^{29}$ Individual patients rationally assess situations and act prudently. They negotiate quietly, and creatively challenge the official rules with their value framework and practical actions. These subversive, indirect actions by patients to circumvent or resist state rules are widespread. Although these daily "resistances" cannot directly change the rules, they do, to some extent, push back the policies that people think did not serve them well. They allow individuals to temporarily seize control of their own situations, and to secure health care access and benefits within the changing system.

29 Ong, Aihwa and Li Zhang, "Introduction: Privatizing China: Powers of the Self, Socialism from Afar," in Privatizing China: Socialism from Afar (Ithaca, 2008), p. 8. 


\section{Using Guanxi to Gain Benefits: the Unequal Insurance Reimbursement}

People display an agentive ability to accommodate to existing policies. Local patients also widely use connections to obtain benefits from health insurance and aid programmes. Yet, these individual agentive efforts make insurance compensation and medical aid inconsistent. The "honest" and less connected patients may easily lose out. The cases of Mrs Lou and Mrs Huang below, demonstrate the huge difference in compensation for similar treatments in the same hospital:

Mrs Lou, a local resident in her 30s, broke her leg in 2011. She was taken into the TCM Hospital soon afterwards. The financial condition of Mrs Lou's family was average. Her husband was working as a porter for a furniture store with a salary of just over 2,000 Yuan a month. Her son was studying in a local middle school. Mrs Lou was a worker in a local textile company, earning just over 1,000 Yuan per month. The company offered employees medical insurance, co-paid by the company and employees. However, Mrs Lou declined the insurance in order to save her portion (dozens Yuan a month) of contribution, because she knew her job was unstable and the insurance would not be lifelong if she left the company before the retirement age ( 55 years old). Moreover, she thought she was young and healthy and would not need medical insurance. As a result, when she got injured in 2011, she did not have any insurance. Luckily, her sister was working in a local health office. The sister helped Mrs Lou register under the name of a relative, who had rural CMS. This well-connected sister also found an acquaintance in the hospital and arranged an experienced senior doctor to operate for Mrs Lou. A steel plate was installed in Mrs Lou's leg. She stayed in the hospital for 19 days. The whole hospitalisation cost over 20,000 Yuan, almost ten times her husband's monthly salary. This huge amount of money was borrowed from relatives. Later, through her sister's connections, she was reimbursed more than 10,000 Yuan, and thus only paid several thousand Yuan outof-pocket. 'It's lucky we got the reimbursement, otherwise, we would be in a very difficult situation. We repaid the borrowed money after receiving the reimbursement'. She told me that now many people were like her, borrowing money for major surgery and repaying the debt after getting reimbursement. "The state policy is good, [it would be better] if there was less corruption at the bottom," she concluded. (From Interview P6 and field notes)

68-year-old Mrs Huang broke her arm in 2010. She and her husband went to the TCM Hospital, and registered under the doctor who they had known for decades. Through this doctor, Mrs Huang was able to register as an inpatient with a hospital bed ready on the day. "If it was not for him, I would not be hospitalised that soon. I might have stayed in the [hospital] corridor waiting for a bed. There were no more beds available. Without connections or extra money, they would not have allowed me 
to go into hospital," Mrs Huang stated these words with gratitude to her doctor. Later on, in surgery, a steel plate was put in Mrs Huang's arm, and she stayed in the TCM Hospital for over 20 days. Her total medical expenses were over 20,000 Yuan. Mrs Huang had rural CMS, but she claimed back less than 4,000 Yuan. "The [imported] steel plate couldn't be reimbursed, the anaesthetic couldn't be reimbursed, the bedding fees were not covered...” Mrs Huang counted to me in detail the items not covered in her case. Her husband, Mr Huang, told me that he learnt from the insurance bureau that injury (shang) received much less reimbursement compared with illness (bing). In Mrs Huang's case, she had been injured. Mr Huang explained that the reimbursement process was related with qing (affection or relationship). "If we have a good relationship, I [the health insurance administrator] will reimburse you [the patient] for those drugs that are not specified by the insurance policy. If we don't have good relationship, I won't reimburse you for these items. You know our family's condition. We didn't have any connection, therefore claimed back only a little," Mr Huang sighed. (From Interview P1, Interview P27, and field notes)

The differentiation of shang (injury) and bing (illness) is a simplification of insurance rules by local insurance officers. The different compensations on injury and illness are based on the division of health care responsibility. While many injuries are directly caused by patients or other individuals' actions, illnesses in many cases are beyond one's personal control. However, this differentiation is not in accordance with people's concept and lived experience of illnesses which include all symptoms and injuries requiring medical care. The implementation of insurance policies thus frequently causes misunderstandings and doubts from patients. Individuals like Mrs Huang suspect that the disparities in insurance compensation among patients were due to guanxi connections. "No matter what you do, you need guanxi and renqing [relationship, affective tie] in this small county," Mr Huang lamented. The staff at the insurance bureau have power to interpret policies according to individual cases. The interpretation and implementation by local administrators have certain arbitrariness and leave space for well-connected individuals to benefit more. In the cases above, Mrs Lou and Mrs Huang had similar injuries, were enrolled in the same hospital, had about the same overall medical expenditure (over 20,000 Yuan), used the same insurance scheme (the rural CMS), but were reimbursed greatly different amounts (more than 10,000 Yuan for Mrs Lou and less than 4,000 Yuan for Mrs Huang). The difference, without denying the impact of the official reimbursement rate that was slightly ( 5 percent) higher in 2011 than in $2010,{ }^{30}$ was largely because of Mrs Lou's sister, who worked in a local health office and had insider knowledge about

30 Local official reimbursement rate of the rural CMS in the county level hospital was 60 percent for medical expenditure beyond 400 Yuan in 2010, and 65 percent for medical expenditure beyond 300 Yuan in 2011. 
how the system worked. With good connections to the doctor, Mrs Lou's sister could ask the doctor to use more medicines that were covered by insurance; with good connections to the health insurance bureau, the items that were not specified by the insurance policy could also be reimbursed. The locals I met invariably agreed that knowing someone in the local medical "circle" was fundamental in getting reliable health care and favourable reimbursement. By using guanxi, Mrs Lou and Mrs Huang were enrolled in the overcrowded hospital in a timely fashion. With good connections, Mrs Lou could use a relative's insurance to receive higher compensation for health care; without connections, Mrs Huang, even with insurance, got a much lower compensation. Through connections, the state-subsidised health care became available for people who was not entitled but was well connected. For people like $\mathrm{Mr}$ and Mrs Huang though, resentment rose when they witnessed others benefit more while those in poor financial status and in need of help benefited much less. While on the surface it seemed that their low reimbursement was due to their mismatched reimbursement criteria, it was actually due to their lack of connections. Without connections to overcome official rules, Mr Huang felt discriminated against, and could only respond by complaining about local implementation and corruption. Even Mrs Lou, who personally benefited from health insurance, consciously criticised possible corruption at the bottom.

The new insurance scheme serves as a mechanism of control, making people more "governable." Yet the "governance" is always open to manoeuvre in local context. In health care access, patients draw upon different forms of capital to secure qualified health care and get insurance benefits. Patients' informal measures to accessing health care and their taking advantage of current policy were morally justified, which helped the "weak" patients benefit in the imperfect system. These actions constitute ordinary peoples' "creative compliance" in daily life when facing social structures that they cannot participate in or cannot reject directly. Agency, though, is always unequally distributed among people, who are embedded in specific social relationships and power structures. The frequent use of guanxi and renqing to take advantage of the "grey area" that is not specified by the policy, contributes to an abundance of arbitrary cases and potential corruption. The new health insurances, that should improve health care equality, contrarily create new injustice and predicaments. The locals question the varied insurance benefits and seek individual channels to overcome obstacles if possible, but can hardly argue against the system arrangement itself. They seek to meet the regulations and standards to become the "qualified" one who is entitled. They creatively use the rules and regulations that already exist in the system, adjusting themselves to strive for inclusion, creating a new dependency that leaves them vulnerable to arbitrary interpretation (by the local administrative agencies). In the process, they reproduce new inequality. 


\section{Discussion and Conclusion: the Making of Governable Subjects and the Reproduction of Inequality}

Since the new healthcare reform in the 2000s, the Chinese government spending on health care has increased rapidly, especially in the area of health insurance. Health insurance allows for patients' medical fees to be partly covered. Recent research shows that, in the new health care reform, the total payment from health insurance programmes was estimated to account for over 50 percent of provider revenue, and over 25 percent of total health expenditure. ${ }^{31}$ However, this same research, alongside another recent study, ${ }^{32}$ shows that the new health insurance schemes have limited effect in reducing patients' health care burden. The rapid increase of overall medical expenditure, the low insurance reimbursement rate, the various regulations and mean-testing, to some extent, offset the effects of medical insurance.

Health insurance schemes are central in shaping people's experiences under the new healthcare reform. They function to integrate the formerly uninsured population, but also marginalise and exclude certain population. Insurance imposes various regulatory rules and criteria to individuals, and those patients who cannot meet or satisfy these criteria are marginalised. The normative categories of insurance recognise some patients' needs but remain blind to others'. Besides, insurance policies still contain rationalities and mechanisms produced in the collective period (that health care was determined by one's place of residence, hukou registration, employment status, etc.), which coexist and conflict with the rationalities of the market era. The over-bureaucratic insurance arrangement and reimbursement procedures exclude certain groups and discourage some patients from obtaining much needed medical aid.

The new health insurance schemes constitute biopower, subjecting patients to a structure of selection and means-testing. Governance is embedded in the health insurance regimes to shape and reshape the conduct of individuals and the population. Insurance policies not only generate "positive and productive forces for the compliance and regulation of the body," ${ }^{33}$ but also produce subtle, punitive techniques to refrain people from violating normative rules. The insurance bureau that determines the qualification of patients is "biobureaucracy," ${ }^{34}$ which exposes people to a set of knowledge, criteria and identifications. Although the

31 Chen Gao, Fei Xu, and Gordon G. Liu, "Payment Reform and Changes in Health Care in China," Social Science \& Medicine, 111 (2014), 10-16.

32 Kai Liu, Qiaobing Wu and Junqiang Liu, "Examining the Association between Social Health Insurance Participation and Patients' Out-of-Pocket Payments in China: The Role of Institutional Arrangement," Social Science \& Medicine 113 (2014), 95-103.

33 Martin Hewitt, "Bio-politics and Social Policy: Foucault's Account of Welfare," Theory, Culture \& Society, 2: 1 (1983), 72.

34 Matthew Kohrman, Bodies of Difference: Experiences of Disability and Institutional Advocacy in the Making of Modern China (Berkeley, 2005). 
deserving/undeserving distinction has a long history in the Chinese party-state's welfare allocation, ${ }^{35}$ the new insurance schemes further categorise patients as being deserving or underserving, qualified or unqualified. There is also a clear division of state and individual responsibilities that it is an individual's responsibility for illnesses and injuries caused by suicide, accidents, fighting, alcohol consumption, criminal actions, etc. The insurance schemes underlie values of self-responsibility, that patients are required to conduct themselves in a responsible manner and to become qualified subjects. These new insurance schemes are thus used by the state as surveillance measures and disciplinary norms to control the population, birth, and individual conduct.

People are not simply passive in submitting to the established rules of insurance, but actively negotiate with these rules and creatively find ways to work around the regulations that attempt to structure and regulate their behaviour. Patients' guanxi work and creative problem-solving efforts unleash the subversive power towards system dominance and normalisation. However, many patients' negotiation ability is limited. They do not resist the structures and criteria of qualification, but refashion themselves to meet the criteria. People demand inclusion rather than claiming inalienable rights. Their successful negotiations have some immediate effects in obtaining benefits, but they can hardly penetrate into the system to make a change. Besides, the eligibility tests of claimants leave space for arbitrary interpretations, leading some people to benefit disproportionally. The criteria and rules are negotiated by those well connected to obtain special rights to health care benefits, while those less connected are further excluded. The inconsistent criteria and categories produce a deepening sense of injustice.

The definitions of eligibilities and qualifications will be an ongoing contention in the unfolding of the new healthcare reform among patients, health professionals, medical institutions, insurance bureaus, and various government departments that administer different insurance schemes. The rapidly mobilising Chinese population needs a renewing of the categories formed by the health insurance system, which are still bound by mechanisms that were formed in the collective era. The insurance benefits in the current healthcare reform still show the state's acknowledgement of individual needs and claims, which are "granted" rather than entitled. Health care that is not based on equal and inalienable rights would create further inequality. It cannot prevent individual existential needs being encroached upon by political and economic needs, and by officially sanctioned programmes (such as birth planning). The right to basic health care cannot depend on the considerations of eligibility or worthiness, but must be based upon the essential vulnerability of the human body, and on the fact that every individual has the right to life.

35 Janet Chen, Guilty of Indigence: The Urban Poor in China, 1900-1953 (Princeton, 2012). Linda Wong, Marginalization and Social Welfare in China (London, 1998). 
Jiong Tu is an assistant professor at the Department of Sociology and Social Work, School of Sociology and Anthropology, Sun Yat-Sen University. 


\section{References}

Becker, Gay, "The Uninsured and the Politics of Containment in U.S. Health Care," Medical Anthropology, 26: 4 (2007), 299-321.

Chen, Juan, "Internal Migration and Health: Re-examining the Healthy Migrant Phenomenon in China," Social Science \& Medicine 72: 8 (2011), 1294-1301.

Chen, Janet, Guilty of Indigence: The Urban Poor in China, 1900-1953. Princeton, NJ: Princeton University Press, 2012.

Ewald, Francois, "Insurance and Risk," pp. 197-210 in G. Burchell, C. Gordon and P. Miller, eds., The Foucault Effect: Studies in Governmentality with Two Lectures by and an Interview with Michel Foucault, Chicago: University of Chicago Press, 1991.

Foucault, Michel. Power/knowledge: Selected interviews and other writings, 1972-1977. New York: Pantheon, 1980.

Gao, Chen, Fei Xu, and Gordon G. Liu, "Payment Reform and Changes in Health Care in China," Social Science \& Medicine, 111 (2014), 10-16.

Greenhalgh, Susan, "Planned Births, Unplanned Persons: 'Population' in the Making of Chinese Modernity," American Ethnologist, 30: 2 (2003), 196-215.

Greenhalgh, Susan, "The Chinese Biopolitical Facing the Twenty-first Century," New Genetics and Society, 28: 3 (2009), 205-222.

Greenhalgh, Susan and Edwin A. Winckler, Governing China's Population: From Leninist to Neoliberal Biopolitics. Stanford, CA: Stanford University Press, 2005. Grogan, Colleen M, "Urban Economic Reform and Access to Health Care Coverage in the People's Republic of China," Social Science \& Medicine, 41: 8 (1995), 1073-1084.

Gu, Xin, Towards Universal Coverage of Healthcare Insurance: The Strategic Choices and Institutional Frameworks of China's New Healthcare Reform (Zouxiang quanmin yibao: zhongguo xin yigai de zhanlue yu zhanshu). Beijing: China Labour and Social Security Publishing House, 2008.

Hesketh, Therese, Xuejun Ye, Lu Li, and Hongmei Wang, "Health Status and Access to Health Care of Migrant Workers in China," Public Health Reports 123: 2 (2008), 189-197.

Hewitt, Martin, "Bio-politics and Social Policy: Foucault's Account of Welfare," Theory, Culture \& Society, 2: 1 (1983), 67-84.

$\mathrm{Hu}$, Xiaojiang, Sarah Cook and Miguel A. Salazar, "Internal Migration and Health in China," The Lancet, 372: 9651 (2008), 1717-1719.

Kohrman, Matthew, Bodies of Difference: Experiences of Disability and Institutional Advocacy in the Making of Modern China. Berkeley: University of California Press, 2005.

Lee, Ching Kwan and Yuan Shen, "The Paradox and Possibility for a Public Sociology of Labor in China," Work and Occupations, 36: 2 (2009), 110-125. 
Liu, Kai, Qiaobing Wu and Junqiang Liu, "Examining the Association between Social Health Insurance Participation and Patients' Out-of-Pocket Payments in China: The Role of Institutional Arrangement," Social Science \& Medicine 113 (2014), 95-103.

Ong, Aihwa and Li Zhang, "Introduction: Privatizing China: Powers of the Self, Socialism from Afar," pp. 1-20 in Privatizing China: Socialism from Afar. Ithaca, NY: Cornell University Press, 2008.

Peng, Yingchun, Wenhu Chang, Haiqing Zhou, Hongpu Hu, and Wannian Liang, "Factors Associated with Health-seeking Behavior among Migrant Workers in Beijing, China," BMC Health Services Research, 10:69 (2010).

Solinger, Dorothy, Contesting Citizenship in Urban China: Peasant Migrants, the State, and the Logic of the Market. Berkeley: University of California Press, 1999. Wang, Shaoguang, "China's Double Movement in Health Care," Socialist Register, 46 (2010), 240-261.

Whyte, M. King, One Country, Two Societies: Rural-urban Inequality in Contemporary China. Cambridge, MA: Harvard University Press, 2010.

Wong, Linda, Marginalization and Social Welfare in China. London: Routledge, 1998.

Wu, Yanrui, "China's Health Care Sector in Transition: Resources, Demand and Reforms," Health Policy, 39: 2 (1997), 137-152.

$\mathrm{Xu}$, Feng, "Governing China's Peasant Migrants: Building Xiaokang Socialism and Harmonious Society," pp. 38-62 in E. Jeffreys, eds., China's Governmentalities: Governing Change, Changing Government, London: Routledge, 2009.

Ying, Xing, "Barefoot Lawyers and Rural Conflicts," pp. 64-82 in Y. T. Hsing and C. K. Lee, eds., Reclaiming Chinese Society: The New Social Activism, New York: Routledge, 2010. 